\title{
Transition Metal Ion Implantation into Diamond-Like Carbon Coatings: Development of a Base Material for Gas Sensing Applications
}

\author{
Andreas Markwitz, ${ }^{1,2}$ Jérôme Leveneur, ${ }^{1}$ Prasanth Gupta, ${ }^{1,2}$ Konrad Suschke, ${ }^{1}$ \\ John Futter, ${ }^{1}$ and Morgane Rondeau ${ }^{1}$ \\ ${ }^{1}$ National Isotope Centre, GNS Science, P.O. Box 31312, Lower Hutt 5010, New Zealand \\ ${ }^{2}$ The MacDiarmid Institute for Advanced Materials and Nanotechnology, Victoria University of Wellington, P.O. Box 600, \\ Wellington 6140, New Zealand \\ Correspondence should be addressed to Andreas Markwitz; a.markwitz@gns.cri.nz
}

Received 10 November 2014; Accepted 19 December 2014

Academic Editor: Joydeep Dutta

Copyright ( 2015 Andreas Markwitz et al. This is an open access article distributed under the Creative Commons Attribution License, which permits unrestricted use, distribution, and reproduction in any medium, provided the original work is properly cited.

\begin{abstract}
Micrometre thick diamond-like carbon (DLC) coatings produced by direct ion deposition were implanted with $30 \mathrm{keV}^{\mathrm{Ar}}{ }^{+}$and transition metal ions in the lower percentage $(<10$ at.\%) range. Theoretical calculations showed that the ions are implanted just beneath the surface, which was confirmed with RBS measurements. Atomic force microscope scans revealed that the surface roughness increases when implanted with $\mathrm{Ar}^{+}$and $\mathrm{Cu}^{+}$ions, whereas a smoothing of the surface from 5.2 to $2.7 \mathrm{~nm}$ and a grain size reduction from 175 to $93 \mathrm{~nm}$ are measured for $\mathrm{Ag}^{+}$implanted coatings with a fluence of $1.24 \times 10^{16} \mathrm{at}^{-\mathrm{cm}^{-2}}$. Calculated hydrogen and carbon depth profiles showed surprisingly significant changes in concentrations in the near-surface region of the DLC coatings, particularly when implanted with $\mathrm{Ag}^{+}$ions. Hydrogen accumulates up to 32 at.\% and the minimum of the carbon distribution is shifted towards the surface which may be the cause of the surface smoothing effect. The ion implantations caused an increase in electrical conductivity of the DLC coatings, which is important for the development of solid-state gas sensors based on DLC coatings.
\end{abstract}

\section{Introduction}

Detection of gases often involves electrochemical and solidstate sensors [1,2]. Solid-state sensors can be fabricated using transition metal oxides, which cause gases to dissociate into charged ions and/or complex molecules [3, 4]. Adsorption and desorption of molecules on the surface of a semiconducting metal oxide induces a change in the charge carrier concentration in the near-surface region which, in turn, leads to change in the material's conductivity. This can be measured with electrical measurements using electrodes on or under or even embedded in the oxide film [5]. Designs usually involve heating elements to achieve optimal temperature for the gas detection [5]. Solid-state sensors offer advantages such as (1) avoiding sensor material consumption, since the sensor returns to its initial state once the gas has desorbed; (2) detection of a large range of gases, depending on the metal oxide and operating temperature; (3) longer life expectancy than catalytic or electrochemical sensors [5]. However, solid-state sensors usually display poor selectivity over the measured gas species and high-sensitivity to humidity [6].

DLC coatings have recently drawn interest for use as electrodes in electrochemical devices due to high stability and chemical inertness along with their very good biocompatibility and potentially being very efficient under aggressive environmental conditions [7]. Sensors using DLC coatings as electrodes show long term stability combined with improved cross sensitivity for interfering gases and susceptibility to changes in environmental conditions [8]. Conductive DLC electrodes coated with hydrophilic, conductive, and porous polytetrafluoroethylene (PTFE) produced high permeable electrodes [5]. A basic solid-state sensor could be devised which contains an electrical circuit that measures resistivity 
changes between electrodes embedded in a DLC coating that has been deposited on an electrically insulating substrate. However, the low chemical reactivity and large resistivity often observed in DLC also mean that its application as a sensing surface in such a sensor is limited. For that purpose, we are currently investigating other methods on how to make DLC materials chemically reactive and preferably specifically reactive to a targeted chemical compound or family of compounds. The low conductivity of DLC also needs to be addressed.

In DLC, the $\pi$ states of $\mathrm{sp}^{2}$ sites form weaker $\pi$ bonds compared to $\sigma$ bonds and also give rise to additional gap states within the $\sigma-\sigma^{*}$ gap [9]. In addition, the electrical properties of DLC are highly influenced by the number and configuration of the $\mathrm{sp}^{2}$ sites in DLC [9]. These $\mathrm{sp}^{2}$ sites are usually clustered in the form of sixfold rings which can further coalesce into larger structures. Disorder can limit the size of such $\mathrm{sp}^{2}$ clusters. Controlling the number of $\mathrm{sp}^{2}$ sites and their configuration can be used as a means to tune the band gap and other electrical properties of DLC materials.

We have taken a new approach to develop a sensor for dihydrogen sulfide $\left(\mathrm{H}_{2} \mathrm{~S}\right)$ using an ion implanted hydrogenated diamond-like carbon (DLC) coating on a silicon wafer based on our recent development of micrometre thick DLC coatings fabricated by direct ion deposition [10-12]. Our DLC coatings contain carbon atoms in $\mathrm{sp}^{2}$ and $\mathrm{sp}^{3}$ states.

We are considering the use of transition metal impurities as reaction sites for $\mathrm{H}_{2} \mathrm{~S}$ on a DLC layer. In this paper, we discuss the changes in the electrical properties of our DLC coatings under various heavy atoms' ( $\mathrm{Ag}, \mathrm{Cu}$, and $\mathrm{Ar}$ ) ion implantation. The transition metals $\mathrm{Cu}$ and $\mathrm{Ag}$ were chosen for the experiments to introduce atoms that have the ability to change the electrical behaviour of the DLC coating. The chemically inert atom Ar was also implanted to study effects of the ion bombardment induced damage on the electrical properties.

\section{Experimental}

2.1. DLC Coatings. DLC coatings were produced by the circular anode layer ion source (CALIS) that was recently developed at GNS Science [10]. The novelty of the ion source is the simultaneous emission of ions in a radial geometry of 360 degrees. The ion source is placed in a cylindrical chamber made of stainless steel under high vacuum. The substrates are placed on the inner surface of the chamber facing the ion source. The source consists of anode and cathode separated by a distance of $2 \mathrm{~mm}$. Permanent magnets are employed inside of the ion source to produce a magnetic field of $0.35 \mathrm{~T}$. The source is powered by a single high voltage power supply to provide high voltage potential between anode and cathode as well as extraction voltage.

Samples were cut from (100) Si and subsequently cleaned with compressed air. No additional cleaning methods were employed. The first step of the deposition process is to establish a base pressure in the chamber $<10^{-5} \mathrm{hPa}$. Once the required pressure is reached, an anode voltage of $1.5 \mathrm{kV}$ is applied. Butane gas is then fed into the source at a constant flow rate to establish a stable plasma. In the experiments, we have used total ion voltages of $4-8 \mathrm{kV}$. The operating gas pressure inside the source was set to $4 \times 10^{-5}$ to $1 \times$ $10^{-4} \mathrm{hPa}$. The gas pressure had to be varied with respect to the extraction voltage to generate a constant beam current of $10 \mathrm{~mA}$. In general, if the extraction voltage is decreased, then the gas pressure has to be increased appropriately to sustain the same ion current. The source is moved horizontally inside the cylindrical chamber at a rate of $1.5 \mathrm{~mm} \mathrm{hr}^{-1}$ throughout the deposition process to ensure lateral uniformity in the coatings. DLC coatings with thickness reaching as high as $5 \mu \mathrm{m}$ are produced using these process parameters. The coatings were deposited at a rate of $70 \mathrm{~nm} \mathrm{~min}^{-1}$. Raman spectroscopy results suggest the presence of disordered DLC layers with $I(\mathrm{D}) / I(\mathrm{G})$ ratio of about $0.7[10]$. The coatings are ideal for implantation studies as they are relatively fast to produce, have a reproducible $\mathrm{C} / \mathrm{H}$ stoichiometry and thickness, and are naturally very smooth [10]. Further deposition process and coating properties are described in $[10,15]$.

2.2. Ion Implantation. The use of ion implantation for doping processes is well established and has several advantages compared to other techniques such as high reproducibility, processing near room temperature, ability to implant any element impurity free into solid substrates (with absence of hydrogen, nitrogen, and oxygen), and avoiding chemical restrictions such as insolubility and stoichiometry. The ion beams were generated in the implanter at GNS Science by a Penning ion source using solid materials, mass selection, electrostatic beam guidance and focussing, electrostatic beam rastering, and a charge integrator controlled process that produces highly reproducible samples $[16,17]$. The transition metal ions were implanted with $30 \mathrm{keV}$ acceleration energy to insert the dopants just below the surface. A scanned ion current of less than $10 \mu \mathrm{A}$ was used to avoid heating effects. Laterally homogeneous implantations were achieved across an area of $13 \mathrm{~mm} \times 13 \mathrm{~mm}$. The implantations took place under high vacuum conditions of $P<10^{-7} \mathrm{hPa}$ enabling contamination-free implantation processes. The fluence $(\Phi)$ that ranged from $\Phi=10^{14}$ to $10^{16}$ at. $\mathrm{cm}^{-2}$ was chosen to create peak concentrations of up to 8.5 at.\%. The Stopping and Range of Ions in Matter (SRIM) and dynamic Transport of Ions in Matter (T-DYN) Monte-Carlo programs were used to calculate fluence-concentration dependencies and implantation profiles $[13,14]$. The advantage of T-DYN is that sputtering and variation in stopping power due to changing elemental compositions are considered. This is particularly important when implanting atoms with lowenergy, where the sputtering yield can be high and the implanted distribution reaches the surface. Additionally, the adjustment of electronic and nuclear stopping power values in the implanted layer with increasing fluence results in more realistic depth profiles of the implanted atoms. SRIM was used to obtain data on stopping power, depth range, and width of the implanted distribution which allows first quick calculations of the fluence-concentration dependency using a Gaussian approximation. 
TABLE 1: Ion implantation parameters and theoretical calculations by SRIM and T-DYN $[13,14]$.

\begin{tabular}{|c|c|c|c|}
\hline Dopant & $\mathrm{Ar}$ & $\mathrm{Cu}$ & $\mathrm{Ag}$ \\
\hline Fluence $\left(\right.$ at. $\mathrm{cm}^{-2}$ ) & $2.24 \times 10^{16}$ & $1.92 \times 10^{16}$ & $1.24 \times 10^{16}$ \\
\hline Peak concentration of dopant using Gaussian approximation model (at.\%) & 10.0 & 10.0 & 10.0 \\
\hline Depth range of $30 \mathrm{keV}$ ions according to SRIM (nm) & 31.5 & 26.6 & 21.7 \\
\hline Longitudinal straggling according to SRIM (nm) & 8.5 & 6.9 & 4.1 \\
\hline \multirow{3}{*}{ Peak concentration calculated by T-DYN (at.\%) } & $\mathrm{Ar}=6.6 \%$ & $\mathrm{Cu}=7.8 \%$ & $\mathrm{Ag}=8.3 \%$ \\
\hline & $C=70.4 \%$ & $\mathrm{C}=72.5 \%$ & $\mathrm{C}=75.6 \%$ \\
\hline & $\mathrm{H}=23 \%$ & $\mathrm{H}=19.8 \%$ & $\mathrm{H}=16.2 \%$ \\
\hline Depth range according to T-DYN (nm) & 33 & 28 & 26 \\
\hline HWHM according to T-DYN (nm) & 14 & 9 & 6 \\
\hline Sputtering yield & 0.77 & 1.11 & 1.43 \\
\hline
\end{tabular}

2.3. Surface Topography. Atomic force microscopy was used to image the surfaces of the DLC coatings as well as measuring the roughness of the coatings in masked and unmasked regions of the samples. A Nanosurf Easyscan 2 atomic force microscope was used [18]. Scans were taken in contact mode using a silicon tip with $17 \mu \mathrm{m}$ height and less than $10 \mathrm{~nm}$ radius. A force of $10 \mathrm{nN}$ was used in the measurements. The scan speed was set to $10 \mu \mathrm{m} \mathrm{s}^{-1}$. Images were recorded with $0.2 \mathrm{~nm}$ height accuracy. The software Gwyddion was used to analyse the images [19].

2.4. Elemental Depth Profiling. The elemental composition and thickness of the coatings were determined with Rutherford Backscattering Spectrometry (RBS) [20]. The measurements were performed with a $2.0 \mathrm{MeV}^{4} \mathrm{He}^{+}$ion beam (ion current $20 \mathrm{nA}$ ) collimated to $1 \mathrm{~mm}$ in diameter using the $3 \mathrm{MV}$ accelerator at GNS Science. A solid-state barrier detector was placed at a backscattering angle of $165^{\circ}$ to record the backscattered particles. The sample surface was oriented to be perpendicular to the incident ion beam during the measurements. However, to avoid channelling, the samples were tilted by $7^{\circ}$. The spectra were analysed with the Rutherford universal manipulation program (RUMP) software [21]. Elemental depth profiles were determined with a $10 \mathrm{~nm}$ surface resolution.

2.5. Electrical Measurements. The four-point probe contact resistance method was used to investigate the electrical properties of the as-grown and implanted DLC coatings using a Jandall universal probe station and a Keithley 236 High Voltage Source Measurement System [22]. Resistance of the samples was retrieved from the current-voltage (IV) characteristic over the -10 to $10 \mathrm{nA}$ region in current driven mode. The distance between the two central points was $1 \mathrm{~mm}$.

\section{Results and Discussion}

3.1. Ion Implantation. The data listed in Table 1 provides information on peak concentration, implantation depth, and width of the depth distribution. An approach using a Gaussian approximation model results in a peak concentration of $10 \%$ for all three ion species using a fluence range from 1.24

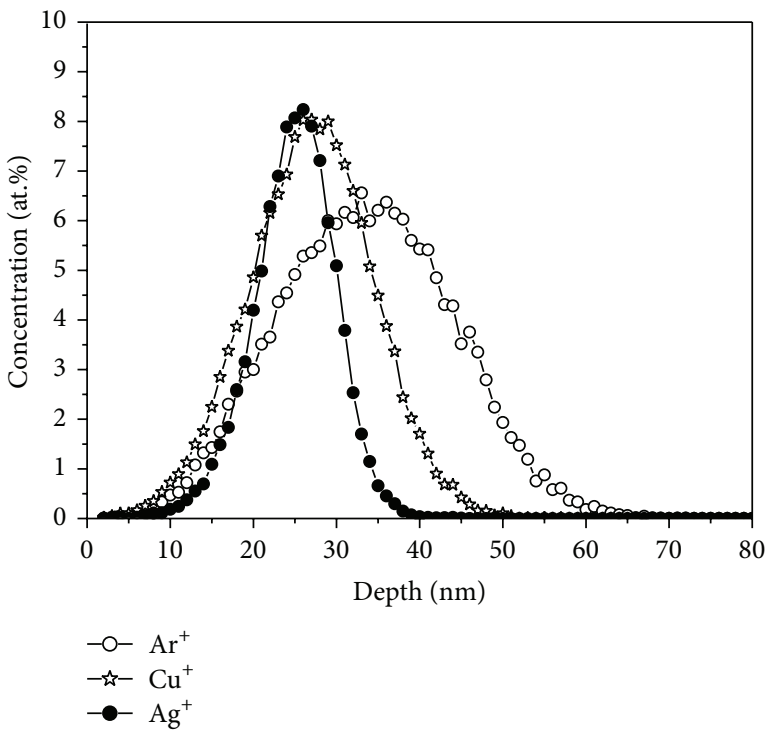

Figure 1: $30 \mathrm{kV}$ Ar, $\mathrm{Cu}$, and Ag depth distributions in DLC coatings $\left(\mathrm{C} / \mathrm{H}=3 ; \rho=1.98 \mathrm{~g} \mathrm{~cm}^{-3}\right)$ calculated with T-DYN.

to $2.24 \times 10^{16}$ at. $\mathrm{cm}^{-2}$. The model uses range and straggling data calculated with SRIM using a DLC coating stoichiometry of $\mathrm{C}_{0.75} \mathrm{H}_{0.25}$ and a material density of $1.98 \mathrm{~g} \mathrm{~cm}^{-3}$ [10]. It can be seen that the ion species range varies from 33 to $22 \mathrm{~nm}$, mainly due to increased stopping power values with respect to ion mass. The width of the distribution is affected similarly by stopping power variations and ranges from 4.1 to $8.5 \mathrm{~nm}$. This data indicates that the ions are implanted into the surface of the DLC coating. T-DYN was used to obtain elemental depth profiles considering varying stoichiometry during implantation and sputtering. The overall result is that the peak concentration is less for all three ion species when compared to the Gaussian model. The variation is 1.7 at. $\%$ for silver, 2.2 at.\% for copper, and 3.4 at.\% for argon. The variation in peak concentration for Ar is due to a slightly deeper centre of the depth distribution ( $33.7 \mathrm{~nm}$ compared to $33.0 \mathrm{~nm}$ ) and a much broader distribution (14 $\mathrm{nm}$ compared to $8.5 \mathrm{~nm}$ ). This is shown in detail in Figure 1. The Ar distribution does not reach the surface-interestingly none of the implanted metals reach the surface. The closest is $\mathrm{Cu}$ with a surface 
concentration of 0.02 at.\%. Less significant variations in peak concentration are calculated for $\mathrm{Cu}$ and $\mathrm{Ag}$. It is interesting to note that the $\mathrm{C}$ and $\mathrm{H}$ composition in the implanted region also changes with ion species as shown in Figure 2. In the case of Ar, the hydrogen concentration in the centre of the ion distribution drops slightly from 25 at.\% to 23 at.\%, whereas, for $\mathrm{Cu}$, the hydrogen concentration drops to 19.8 at.\% and even to 16.2 at.\% for Ag. The calculated $\mathrm{H}$ depth profiles are shown in the inset in Figure 2. Note that the hydrogen concentration in the surface increases significantly. For Ag, the $\mathrm{H}$ concentration increases to 32 at. $\%$, which is an overall increase of $28 \%$. This trend is seen for all three ion species. The carbon depth profiles are decreasing accordingly with the increase in concentration of hydrogen and metal ion distributions at the surface. Similar, but less pronounced, are increases in $\mathrm{C}$ concentrations in the depth following the implanted region; for example, $\mathrm{C}$ increased to 76 at.\% from 20 to $30 \mathrm{~nm}$ for DLC coatings implanted with $\mathrm{Cu}$ and Ar. It is noted that the fraction of $\mathrm{sp}^{3}$ bond increases with increasing $\mathrm{Ag} / \mathrm{C}$ and $\mathrm{Cu} / \mathrm{C}$ ratio [23].

The sputtering yield is dependent on the ion species. According to theory, the sputtering yield increases with atomic mass. Values of $0.77,1.11$, and 1.43 are calculated for $30 \mathrm{keV} \mathrm{Ar}, \mathrm{Cu}$, and $\mathrm{Ag}$ implanted into DLC coatings with $\mathrm{C} / \mathrm{H}$ stoichiometry of 3 and density of $1.98 \mathrm{~g} \mathrm{~cm}^{-3}$. Although the sputtering value is usually quite similar during the calculation, it can change due to varying elemental composition at the surface. In our case, the compositional changes in $\mathrm{H}$ and $\mathrm{C}$ concentrations near the surface cause the sputtering yield to decrease during the calculation. An example is $30 \mathrm{keV} \mathrm{Ag}^{+}$implanted into DLC coating where the sputtering yield decreases from 1.48 to 1.43 for fluences $\Phi=1.24 \times 10^{15}$ to $1.24 \times 10^{16}$ at. $\mathrm{cm}^{-2}$. T-DYN also provides data for the fraction of ion energy transmitted into damage and backscattered particles. Backscattering is low at $30 \mathrm{keV}$; in fact zero particles were calculated to be backscattered for $\mathrm{Ag}$. The majority of the energy goes into damage $(92.85 \%)$ causing significant atom displacement in the implanted layer.

3.2. Surface Topography. Atomic force microscopy (AFM) was used to image the surface of the implanted DLC coatings. The average surface roughness of the as-grown DLC coatings on (100) wafer silicon is $5 \pm 2 \mathrm{~nm}$ for $3 \mu \mathrm{m}$ coating thickness. The average surface roughness is thickness dependent and increases with thickness enabling a growth of structures. As the coatings increase in thickness, a grain-like appearance is observed [10].

Figure 3 shows a typical image of the surface of a DLC coating implanted with $30 \mathrm{keV} \mathrm{Cu}^{+}$using a fluence of $\Phi=$ $1.92 \times 10^{16} \mathrm{~cm}^{-2}$. The ion implantation causes an average increase in surface roughness for implantations with $\mathrm{Cu}$ and Ar ions but a decrease for $\mathrm{Ag}$ ions. Considering the height accuracy of $0.2 \mathrm{~nm}$, the surface roughness increases from 4.7 to $8.3 \mathrm{~nm}$ for $\mathrm{Ar}$ and from 7.7 to $10.0 \mathrm{~nm}$ for $\mathrm{Cu}$ from the as deposited condition to the maximum fluence. In case of the Ag implantation, the roughness decreased from 5.2 to $2.7 \mathrm{~nm}$. This is a significant finding considering that the ion implantation process is a cold temperature process, where the

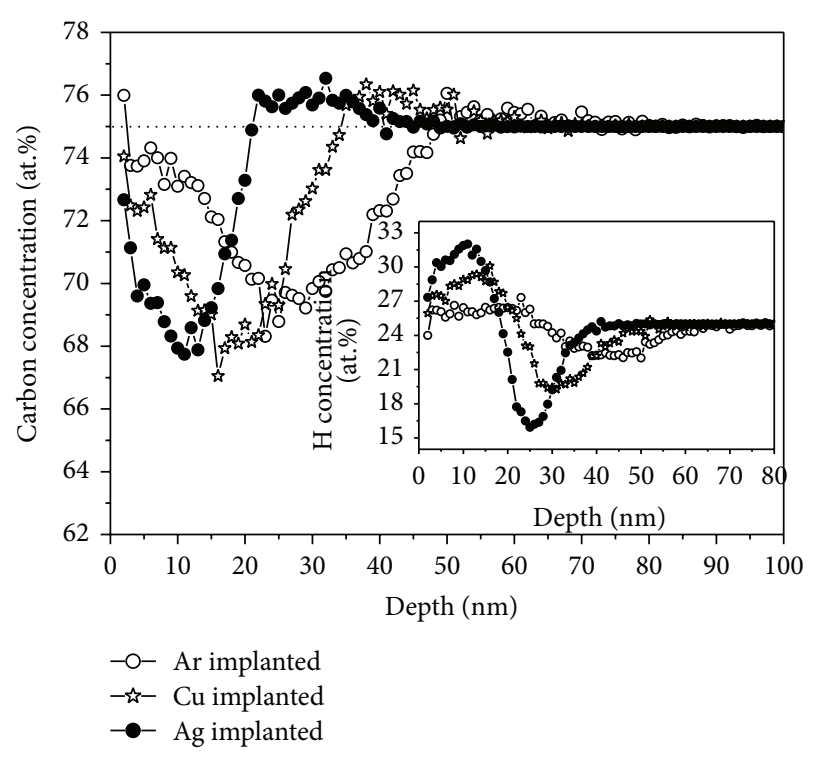

Figure 2: Carbon depth profiles of DLC coatings implanted with $30 \mathrm{kV} \mathrm{Ar}, \mathrm{Cu}$, and Ag calculated with T-DYN. The inset shows the corresponding simulated hydrogen depth profiles. The dashed line indicates the nominal C concentration of the DLC coatings.

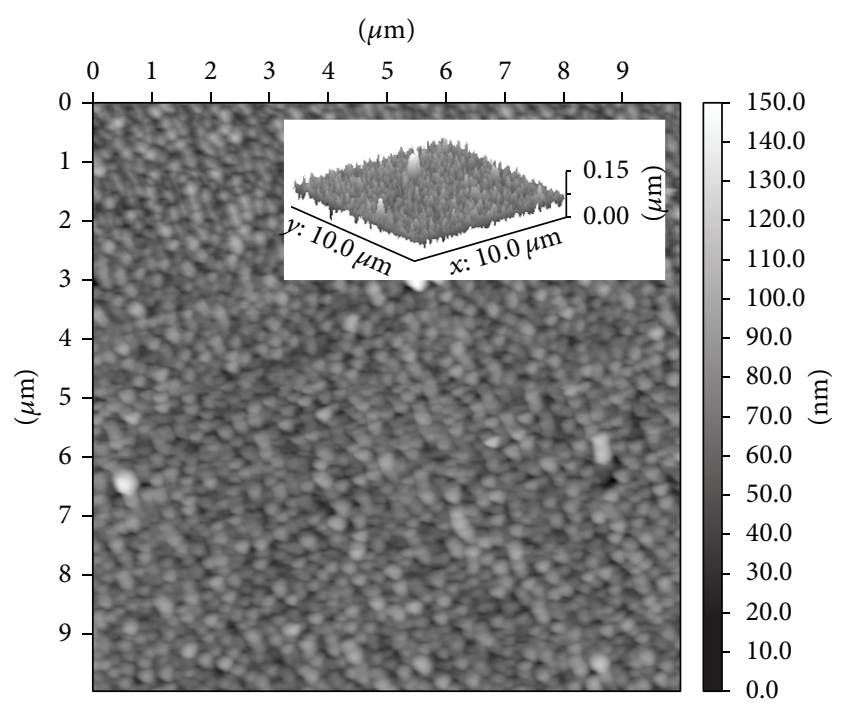

FIGURE 3: Representative image of the surface of a DLC coating implanted with $30 \mathrm{kV} \mathrm{Cu}$ using the fluence of $\Phi=1.92 \times 10^{16}$ at. $\mathrm{cm}^{-2}$.

temperature of the sample does not increase by more than $20^{\circ} \mathrm{C}$ during the implantation process. Analysis of the AFM data regarding grain size reveals a similar trend on the surface roughness. As-grown coatings have an average grain size of $175 \pm 10 \mathrm{~nm}$. The grain size increases to $229 \pm 10 \mathrm{~nm}$ for $\mathrm{Ar}$ and $212 \pm 10 \mathrm{~nm}$ for $\mathrm{Cu}$ but decreases to $93 \pm 10 \mathrm{~nm}$ for $\mathrm{Ag}$. These data were obtained across an area of $100 \mu \mathrm{m}^{2}$.

Sputtering during the ion implantation can lead to smoothing or roughening of the surface, even at normal incidence from the substrate depending on ion species, incidence energy, and target substrate [24-26]. The rough 
surfaces as seen in Figure 3 present many non-normal facets to the incident beam.

Another effect to consider here is the change in stoichiometry of the DLC layer. The coatings were implanted with $1.24-2.24 \times 10^{16}$ at. $\mathrm{cm}^{-2}$. As shown in Figures 1 and 2, implanting DLC coatings with $30 \mathrm{keV}$ Ar results in a buried Ar depth profile which is followed by expected C and $\mathrm{H}$ depth profiles. Even for $\mathrm{Cu}$, the $\mathrm{Cu}$ profile does not reach the surface. However, $\mathrm{H}$ is significantly increased in the near-surface region and $\mathrm{C}$ is decreased. The effect becomes most significant for the $30 \mathrm{keV} \mathrm{Ag}^{+}$implantation into DLC coatings. The Ag concentration profile is relatively sharp and narrow; however, the hydrogen profile is bulged in the near-surface region to a significant concentration of 32 at.\%. Also the $\mathrm{C}$ depth profile is only reaching $73 \%$ at the surface. While the production method has a large role to play in the roughness, general trends have been observed between the hydrogen content and the surface roughness of hydrogenated amorphous carbon layers [27-29]. Hydrogen plays an important role in passivating the dangling bonds of carbon atoms. This would facilitate the formation of $\mathrm{sp}^{3}$ hybridised carbon chains. Increase in $\mathrm{sp}^{3}$ hybridisation is correlated to decrease in surface roughness [28]. Hence, lower roughness values are usually found with higher hydrogen content. Therefore the increased presence of hydrogen in the near-surface region along with reduced $\mathrm{C}$ concentration and buried Ag may be responsible for smoothing of the surface. As described in Experimental, T-DYN does not consider diffusion sinks nor does the program attempt to move atoms according to chemical preferences and chemical compounds. Other techniques, such as pulsed cathodic arc deposition, have also shown smoothing effects when using Ag in a$\mathrm{C}: \mathrm{H}$ films [30]. This was attributed to enhanced diffusion associated with the interaction of energetic carbon and silver ions.

Additional contributions to changes in topography from the implantation are direct heating of the DLC layer and formation of a metallic precipitate on the surface. As discussed, metal ion implantation with $6 \mu \mathrm{A} \mathrm{cm}^{-2}$ does not heat the sample significantly. Greater thermal spikes are expected from larger ion species. However, expected changes would lead to increases in $\mathrm{sp}^{2}$ cluster chain size and roughness. Formation of a nanostructured precipitate can occur once the implanted concentration reaches values above a concentration threshold. In the present case, the formation of a nanoprecipitate is likely with the larger implantation fluence of $\mathrm{Cu}$ and Ag. However, the observed changes in topography are opposite to what would be expected from precipitation. In addition, the implanted fluence remains too small to reach a significant amount of precipitate formation on the surface as shown by the T-DYN simulations above. The threshold value depends on the atomic radii of the dopants and interaction of dopants with the amorphous matrix [31].

3.3. Depth Profiling with RBS. Rutherford backscattering spectrometry was used to measure the dose of the implanted ions. Figure 4 shows depth profiles of DLC implanted with $30 \mathrm{keV} \mathrm{Ag}^{+}$ions from $1.24 \times 10^{14}$ to $1.24 \times 10^{16}$ at. $\mathrm{cm}^{-2}$.

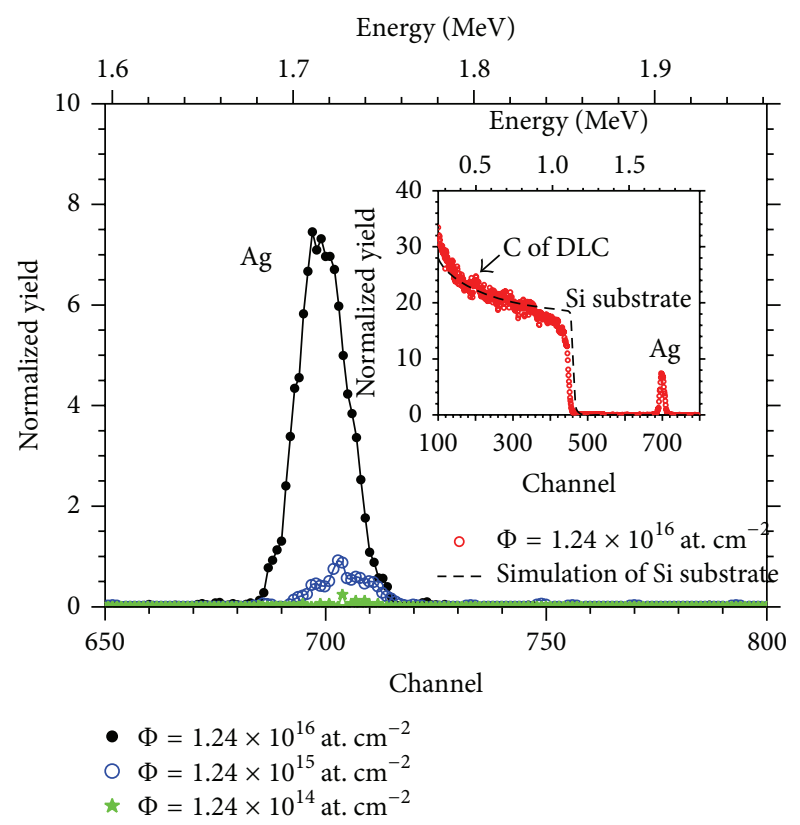

FIGURE 4: Silver depth profiles measured with RBS in the region of the Ag peak using a $2 \mathrm{MeV}^{4} \mathrm{He}^{+}$ion beam. The inset shows the RBS spectrum of a DLC coating on silicon implanted with $\operatorname{Ag} \Phi=1.24 \times$ $10^{16}$ at. $\mathrm{cm}^{-2}$. The dashed line shows the Si substrate.

As can be seen, the Ag peak at about channel 700 in the RBS spectrum increases with fluence. The DLC coating is indicated in the inset by a carbon peak and a shift of the $\mathrm{Si}$ depth profile. A dashed line indicates the expected simulation of an unimplanted Si substrate. The depth resolution of RBS is about $10 \mathrm{~nm}$ using a $2.0 \mathrm{MeV}^{4} \mathrm{He}^{+}$ion beam which resolves the Ag depth distribution, as can be seen in the spectra. An analysis of the spectra with RUMP showed that the dose is similar to the fluence within statistic and systematic errors. For example, the dose $(D)$ of the DLC coating implanted with the fluence of $\Phi=1.24 \times 10^{16}$ at. $\mathrm{cm}^{-2}$ is measured as $D=1.35 \times 10^{16}$ at. $\mathrm{cm}^{-2}$. The RBS simulation considers a DLC layer on silicon with a surface layer that has been implanted with Ag; in the case of 0.1 at.\%, the thickness of this layer is $220 \times 10^{15}$ at. $\mathrm{cm}^{-2}$. This converts to $22 \mathrm{~nm}$ considering a volume density of $9.93 \times 10^{22}$ at. $\mathrm{cm}^{-3}$, which is in general agreement with the T-DYN simulations. The simulation also shows an interface layer between the DLC coating and the silicon substrate that has a mixed composition with silicon enriched to $50 \%$. This is in agreement with previous findings where a mixed DLC/Si layer is observed at the interface [11].

3.4. Electrical Measurements. The four-probe method was used to measure electrical properties of as-grown and ion implanted DLC coatings. The first result is that as-grown coatings have very high resistance. The resistance is measured to be in the G $\Omega$ range. DLC coatings show a large variety of resistivity (range $10^{2}-10^{16} \Omega \mathrm{cm}$ ) depending on the production method and $\mathrm{sp}^{2}$ carbon site configuration [10, 32]. Figure 5 shows the IV characteristic for DLC coatings implanted with $30 \mathrm{keV} \mathrm{Ag}{ }^{+}, \mathrm{Cu}^{+}$, and $\mathrm{Ar}^{+}$in the range from 
TABLE 2: Change in resistance of DLC coatings implanted with Ar, $\mathrm{Cu}$, and $\mathrm{Ag}$ ions in dependence of ion species and fluence.

\begin{tabular}{lcc}
\hline Dopant ion & Fluence $\left(\right.$ at. $\left.\mathrm{cm}^{-2}\right)$ & $R_{\text {as-grown }} / R_{\text {implanted }}$ \\
\hline $\mathrm{Ar}$ & $2.24 \times 10^{14}$ & $2.6 \pm 0.5$ \\
$\mathrm{Ar}$ & $2.24 \times 10^{15}$ & $8.7 \pm 1.7$ \\
$\mathrm{Ar}$ & $2.24 \times 10^{16}$ & $679 \pm 140$ \\
$\mathrm{Cu}$ & $1.92 \times 10^{14}$ & $29 \pm 6$ \\
$\mathrm{Cu}$ & $1.92 \times 10^{15}$ & $149 \pm 30$ \\
$\mathrm{Cu}$ & $1.92 \times 10^{16}$ & $66200 \pm 1300$ \\
$\mathrm{Ag}$ & $1.24 \times 10^{14}$ & $0.9 \pm 0.2$ \\
$\mathrm{Ag}$ & $1.24 \times 10^{15}$ & $17 \pm 3$ \\
$\mathrm{Ag}$ & $1.24 \times 10^{16}$ & $3.1 E 5 \pm 6000$ \\
\hline
\end{tabular}

$-1 \times 10^{-8}$ to $1 \times 10^{8} \mathrm{~A}$. The implanted coatings show resistance that is several orders of magnitude lower compared to the as-grown coatings. Table 2 lists the change in resistance in dependence of dopant and fluence. The $R_{\text {as-grown }} / R_{\text {implanted }}$ ratio indicates that the conductivity increases with concentration for all three dopants considering the variations in the thickness of the coatings. Copper and Ag implanted DLC coatings have a better conductance than Ar implanted DLC. Changes induced from Ar ion implantation are likely to be caused solely by damage in the coatings and increased formation of $\mathrm{sp}^{2}$ clusters. However $\mathrm{Ag}$ and $\mathrm{Cu}$ introduce additional effects such as formation of a metallic precipitate and increase of hydrogen content near the surface. Silver and $\mathrm{Cu}$ ions would most likely not form stoichiometric carbide compounds, such as $\mathrm{CuC}_{2}$ and $\mathrm{Ag}_{2} \mathrm{C}_{2}$ during implantation $[31,33]$. At low fluences, the implanted atoms will be diluted in the solid matrix. Unlike the chemically inert Ar atoms, some chemical bonds are expected between the implanted $\mathrm{Cu} / \mathrm{Ag}$ atoms and $\mathrm{C} / \mathrm{H}$ atoms and compounds from the DLC matrix. The charge transport in the implanted DLC coating is changed by the presence of $\mathrm{Ag}$ and $\mathrm{Cu}$ atoms. At low fluence and depending on their oxidation state, $\mathrm{Ag}$ and $\mathrm{Cu}$ will contribute differently to the charge carrier concentration. The precipitation of a metallic precipitate will decrease the resistance through hopping. Metal-induced gap states are also likely to further reduce the resistivity [31]. The implantation fluences are likely to be too small for the precipitate to reach the percolation threshold, explaining high resistances still observed in the film. Further, imaging will be performed to confirm the distribution of the suspected nanoprecipitate. DLC coatings implanted with Ag atoms implanted to $10 \%$ show a higher conductivity compared to DLC coatings implanted with $\mathrm{Cu}$ atoms. The increase in hydrogen content is likely to increase the resistivity [28] which is not sufficient in the present case to overcome the increase in conductivity from the other contributions.

\section{Conclusions}

DLC coatings were implanted with transition metal ions to investigate a new route for manufacturing gas sensors with DLC. Micrometre thick coatings were implanted with $30 \mathrm{keV} \mathrm{Cu}^{+}$and $\mathrm{Ag}^{+}$ions. Argon ions were also implanted

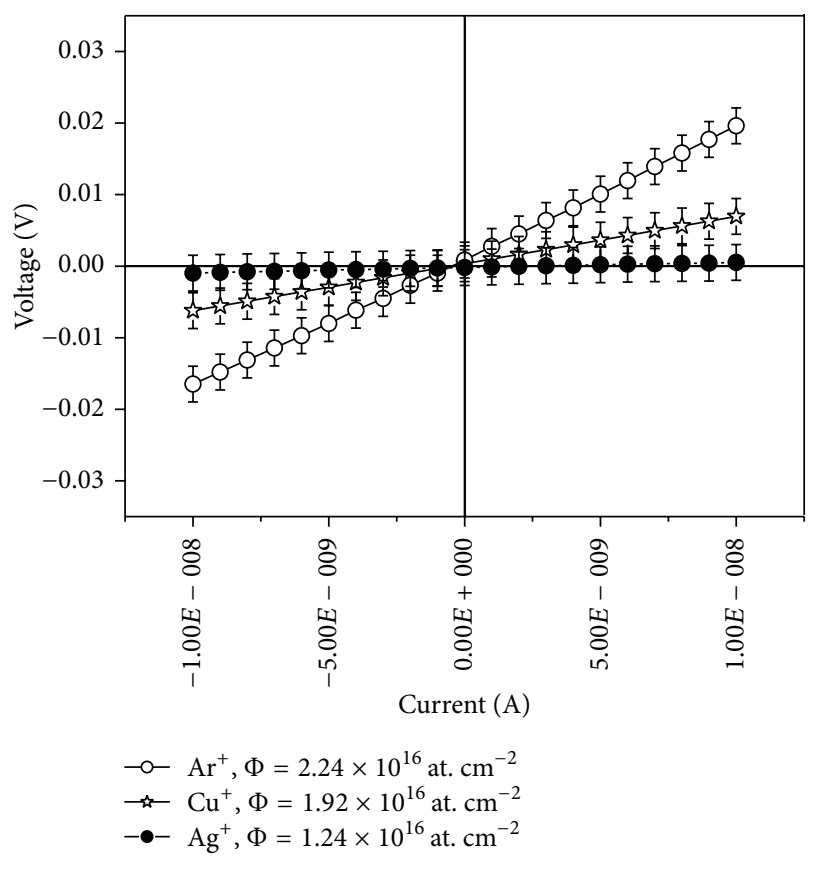

FIGURE 5: IV characteristic for DLC coatings implanted with $30 \mathrm{keV} \mathrm{Ar}{ }^{+}, \mathrm{Cu}^{+}$, and $\mathrm{Ag}^{+}$ions.

with the same energy. It was found that the hydrogen concentration near the surface of the Ag implanted samples increases from 25 to 32 at.\% which leads to a smoothing of the surface from 5.2 to $2.7 \mathrm{~nm}$. The grain size also decreases from 175 to $93 \mathrm{~nm}$. However Ar and $\mathrm{Cu}$ implanted coatings show an increase in average surface roughness and grain size. Electrical measurements show that the as-grown DLC coatings are highly resistive. The resistance ratio between as-grown and implanted DLC coatings shows that the conductivity increases with concentration for all three dopants. Copper and Ag implanted DLC coatings have a better conductance than Ar implanted DLC. This can be explained by Ar causing only damage in the coatings while $\mathrm{Ag}$ and $\mathrm{Cu}$ additionally introduce effects which alter the resistance further. The results illustrate a first step towards using DLC coatings implanted with transition metals for fabricating gas sensors with high stability, chemical inertness, and very good biocompatibility potentially being very efficient under aggressive environmental conditions.

\section{Conflict of Interests}

The authors declare that there is no conflict of interests regarding the publication of this paper.

\section{Acknowledgments}

The project was supported by a grant from the Ministry of Business, Innovation and Employment, New Zealand, for Titanium and related metals development (MBIE-CONT29496-HVMSET-UOW), the GNS Science core science area programme in materials development and SDF-L13-20, the 
MacDiarmid Institute for Advanced Materials and Nanotechnology (New Zealand Centre of Research Excellence), and GNS Science capital expenditure grants during 2013 and 2014. The authors wish to acknowledge Berit Mohr for fruitful discussion.

\section{References}

[1] G. Korotcenkov, Handbook of Gas Sensor Materials Properties, vol. 1, Springer, New York, NY, USA, 2013.

[2] M. Fleischer and M. Lehmann, Solid State Gas SensorsIndustrial Application, vol. 11, Springer, 2012.

[3] A. Afzal, N. Cioffi, L. Sabbatini, and L. Torsi, " $\mathrm{NO}_{x}$ sensors based on semiconducting metal oxide nanostructures: progress and perspectives," Sensors and Actuators B, vol. 171-172, pp. 2542, 2012.

[4] F. Fang, J. Futter, A. Markwitz, and J. Kennedy, "UV and humidity sensing properties of $\mathrm{ZnO}$ nanorods prepared by the arc discharge method," Nanotechnology, vol. 20, no. 24, Article ID 245502, 2009.

[5] M. Nebel, S. Neugebauer, H. Kiesele, and W. Schuhmann, "Local reactivity of diamond-like carbon modified PTFE membranes used in $\mathrm{SO}_{2}$ sensors," Electrochimica Acta, vol. 55, no. 27, pp. 7923-7928, 2010.

[6] G. Korotcenkov, "Gas response control through structural and chemical modification of metal oxide films: state of the art and approaches," Sensors and Actuators B: Chemical, vol. 107, no. 1, pp. 209-232, 2005.

[7] S. C. H. Kwok, W. Zhang, G. J. Wan, D. R. McKenzie, M. M. M. Bilek, and P. K. Chu, "Hemocompatibility and anti-bacterial properties of silver doped diamond-like carbon prepared by pulsed filtered cathodic vacuum arc deposition," Diamond and Related Materials, vol. 16, no. 4-7, pp. 1353-1360, 2007.

[8] P. K. Guha and S. Santra, Semiconductor Gas Sensor, Woodhead Publishing Series in Electronic and Optical Materials, Edited by: J. W. Gardener, Woodhead Publishing, 2013.

[9] J. Robertson, "Gap states in diamond-like amorphous carbon," Philosophical Magazine B, vol. 76, no. 3, pp. 335-350, 1997.

[10] P. P. Murmu, A. Markwitz, K. Suschke, and J. Futter, "A novel radial anode layer ion source for inner wall pipe coating and materials modification-hydrogenated diamond-like carbon coatings from butane gas," Review of Scientific Instruments, vol. 85, no. 8, p. 085118, 2014.

[11] A. Markwitz, B. Mohr, D. F. Carpeño, and R. Hübner, "Ultrasmooth diamond-like carbon coatings with high elasticity deposited at low temperature by direction beam deposition," Surface and Coatings Technology, vol. 258, pp. 956-962, 2014.

[12] A. Markwitz, B. Mohr, and J. Leveneur, "Room temperature diamond-like carbon coatings produced by low energy ion implantation," Nuclear Instruments and Methods in Physics Research: Section B, vol. 331, pp. 144-148, 2014.

[13] http://www.srim.org/.

[14] J. P. Biersack and L. G. Haggmark, "A Monte Carlo computer program for the transport of energetic ions in amorphous targets," Nuclear Instruments and Methods, vol. 174, no. 1-2, pp. 257-269, 1980.

[15] K. Suschke, R. Hübner, P. P. Murmu, P. Gupta, J. Futter, and A. Markwitz, "Growth of diamond-like carbon coatings produced by a 360 degree circular anode layer ion source," submitted to Current Nanoscience.
[16] A. Markwitz, S. Johnson, and M. Rudolphi, "Simultaneous formation of $\mathrm{SiC}$ and $\mathrm{Si}$ nanostructures on silicon by local ion implantation and electron beam annealing," Applied Physics Letters, vol. 89, no. 15, Article ID 153122, 2006.

[17] A. Markwitz, H. Baumann, W. Grill, A. Knop, E. F. Krimmel, and K. Bethge, "Investigations of ultrathin silicon nitride layers produced by low-energy ion implantation and EB-RTA," Nuclear Instruments and Methods in Physics Research B, vol. 89, no. 1-4, pp. 362-368, 1994.

[18] http://www.nanosurf.com/?content=0402.

[19] 2014, http://gwyddion.net/.

[20] A. Markwitz, "Depth profiling: RBS versus energy-dispersive Xray imaging using scanning transmission electron microscopy," Nuclear Instruments and Methods in Physics Research, Section B: Beam Interactions with Materials and Atoms, vol. 161-163, pp. 221-226, 2000.

[21] http://www.genplot.com/.

[22] Keithley, A Tektonix Company, 2014, http://www.keithley.nl/.

[23] Y. Pauleau, F. Thièry, V. V. Uglov, V. M. Anishchik, A. K. Kuleshov, and M. P. Samtsov, "Tribological properties of copper/carbon films formed by microwave plasma-assisted deposition techniques," Surface and Coatings Technology, vol. 180-181, pp. 102-107, 2004.

[24] M. A. Makeev, R. Cuerno, and A.-L. Barabási, "Morphology of ion-sputtered surfaces," Nuclear Instruments and Methods in Physics Research, Section B: Beam Interactions with Materials and Atoms, vol. 197, no. 3-4, pp. 185-227, 2002.

[25] K. Oyoshi, T. Tagami, and S. Tanaka, "Smoothing of silica glass surfaces by ion implantation," Japanese Journal of Applied Physics, vol. 30, no. 8, pp. 1854-1859, 1991.

[26] G. Carter and V. Vishnyakov, "Roughening and ripple instabilities on ion-bombarded Si," Physical Review B, vol. 54, no. 24, pp. 17647-17653, 1996.

[27] J. Robertson, "Requirements of ultrathin carbon coatings for magnetic storage technology," Tribology International, vol. 36, no. 4-6, pp. 405-415, 2003.

[28] D. Liu, Y. Liu, and B. Chen, "Surface roughness of various diamond-like carbon films," Plasma Science \& Technology, vol. 8, no. 6, p. 701, 2006.

[29] S. Pisana, C. Casiraghi, A. C. Ferrari, and J. Robertson, "Roughness evolution during growth of hydrogenated tetrahedral amorphous carbon," Diamond and Related Materials, vol. 15, no. 4-8, pp. 898-903, 2006.

[30] H.-S. Zhang, J. L. Endrino, and A. Anders, "Comparative surface and nano-tribological characteristics of nanocomposite diamond-like carbon thin films doped by silver," Applied Surface Science, vol. 255, no. 5, pp. 2551-2556, 2008.

[31] B. F. Dorfman, "Critical parameters of percolation in metaldielectric diamond-like composites of atomic scale," Thin Solid Films, vol. 330, no. 2, pp. 76-82, 1998.

[32] A. Grill, V. Patel, and S. Cohen, "Electrical resistivities of diamond-like carbon," Diamond and Related Materials, vol. 3, no. 3, pp. 281-284, 1994.

[33] C.-C. Chen and F. C.-N. Hong, "Structure and properties of diamond-like carbon nanocomposite films containing copper nanoparticles," Applied Surface Science, vol. 242, no. 3-4, pp. 261-269, 2005. 

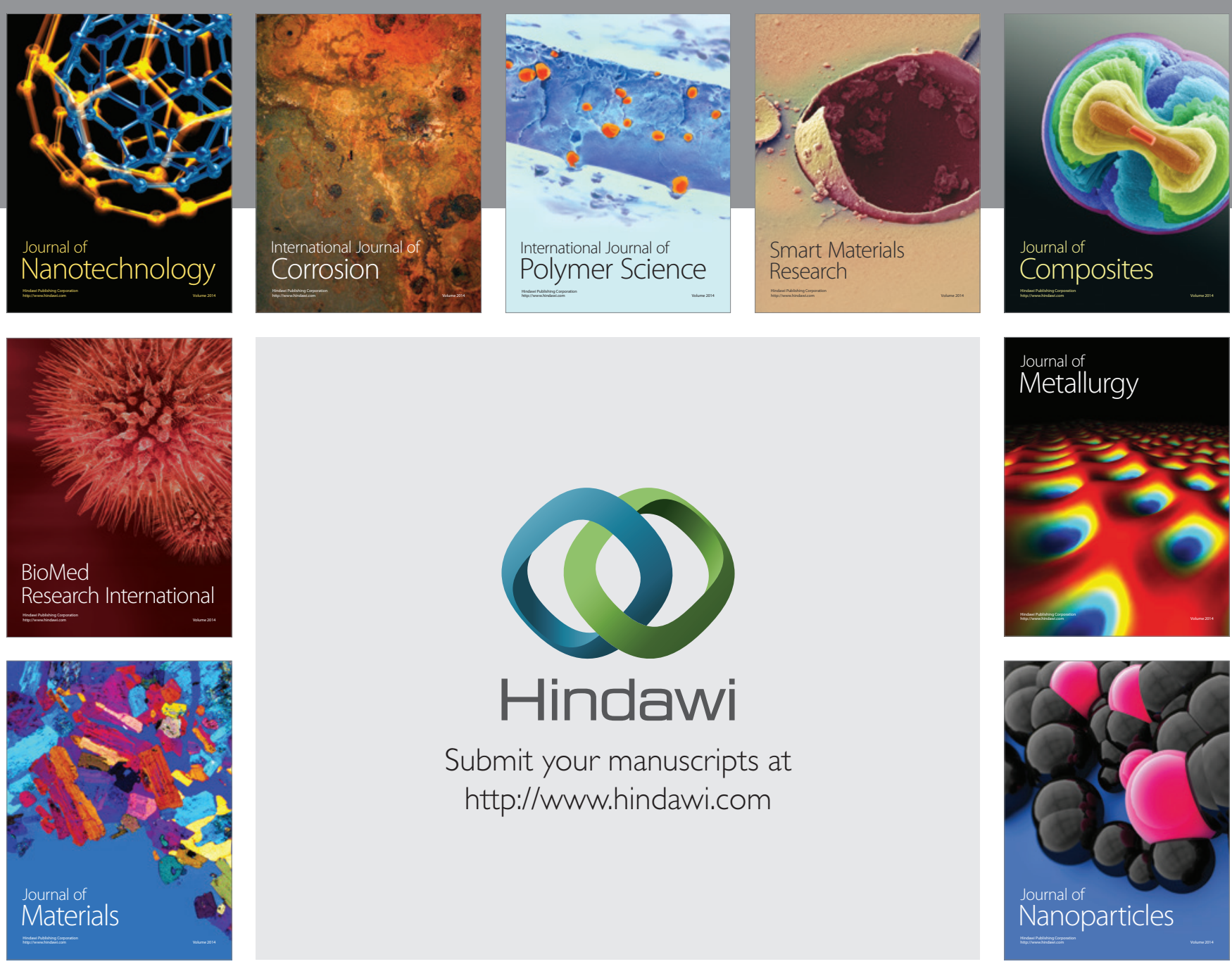

Submit your manuscripts at http://www.hindawi.com
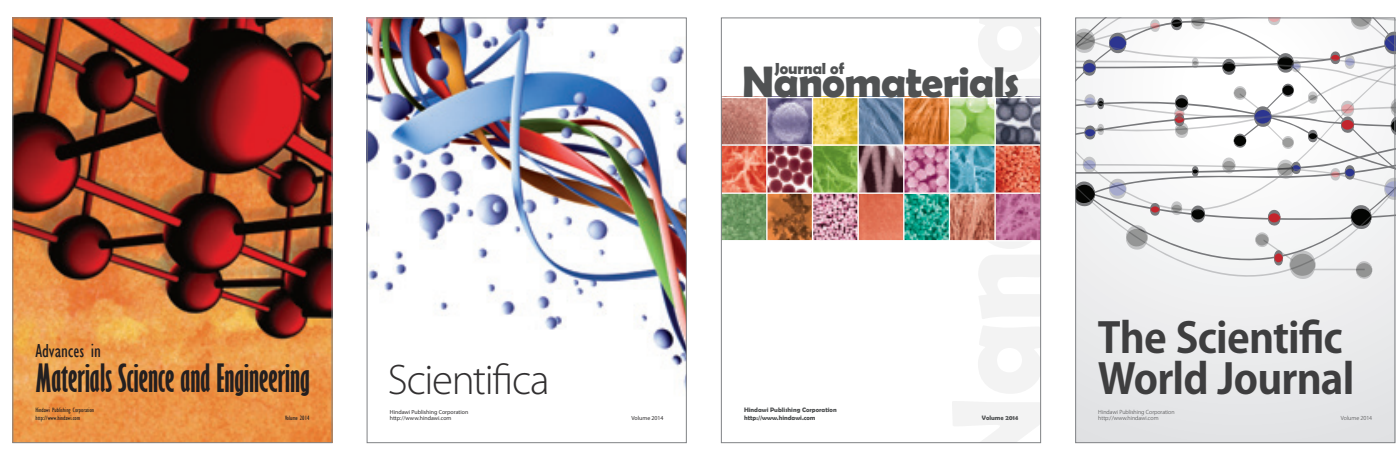

\section{The Scientific World Journal}
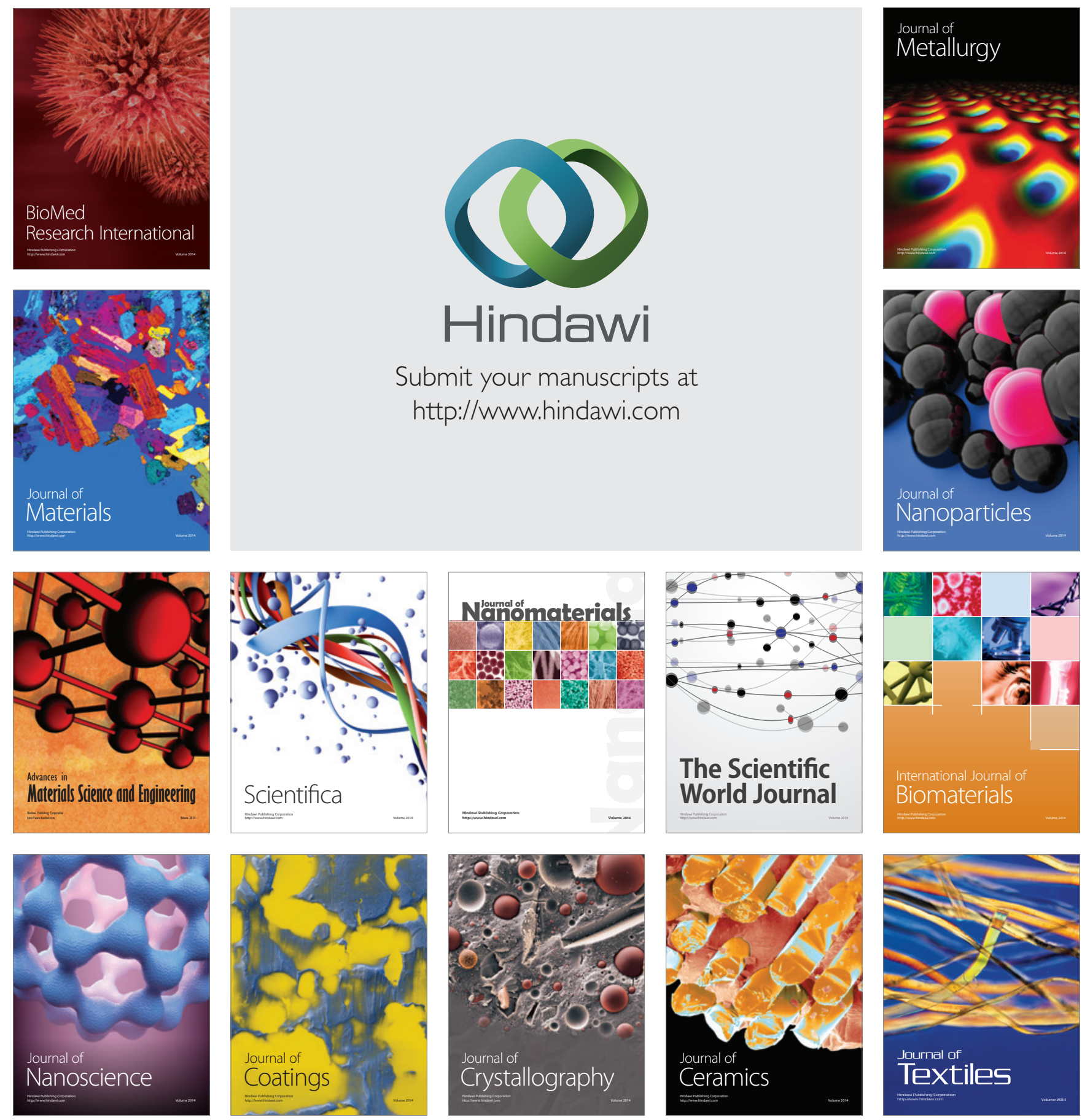